\title{
Commentary: Acute Tension-Type Headaches Are Associated with Impaired Cognitive Function and More Negative Mood
}

\author{
Marcelo M. Valença* \\ Neurosurgery and Neurology Unit, Federal University of Pernambuco, Recife, Pernambuco, Brazil
}

Keywords: headache disorders, primary, moon, tension-type headache, severity, performance

A commentary on

Acute tension-type headaches are associated with impaired cognitive function and more negative mood

OPEN ACCESS

Edited by:

Vincenzo Guidetti,

University of Rome, Italy

Reviewed by:

Stephanie J. Nahas,

Thomas Jefferson University, USA

Umberto Balottin,

University of Pavia, Italy

*Correspondence:

Marcelo M. Valença mmvalenca@yahoo.com.br

Specialty section: This article was submitted to Headache Medicine and Facial

Pain, a section of the journal

Frontiers in Neurology

Received: 13 May 2016 Accepted: 15 June 2016 Published: 30 June 2016

Citation:

Valença MM (2016) Commentary: Acute Tension-Type Headaches Are Associated with Impaired Cognitive Function and More Negative Mood.

Front. Neurol. 7:103.

doi: 10.3389/fneur.2016.00103 by Smith AP. Front Neurol (2016) 7:4. doi: 10.3389/fneur.2016.00042

I found Smith's article (1) extremely interesting. The author reported that an acute attack of tensiontype headache (TTH) may be "associated with an increase in negative affect, poorer performance on working memory and semantic memory tasks, slower psychomotor performance, and increased distraction from irrelevant stimuli" (1).

Although there are a number of articles dealing with cognition/behavior in headache patients (2-4), there is still a consensus that the two most frequent primary headaches, migraine and TTH (5), do not significantly affect cognitive functions to a degree that daily activities are seriously affected, particularly when one considers the interictal periods.

It is well known that migraine attacks are incapacitating, whereas the TTH attacks are mild or moderate in intensity, not affecting the activities of everyday life. In fact, patients with TTH may suffer severe headache attacks, resulting in impairment of routine activities. In a study carried out in our university (6), involving 121 female nurses, 536 headache attacks were registered, 117 with features of TTH and 10 of probably TTH, 3 of these 127 attacks (2.4\%) were considered severe.

Considering that headache attacks are relatively frequent, and the fact that they may impair cognitive function, the physician should consider prophylactic measures to avoid triggering attacks during the performance of important tasks, in particular, those that demand a high level of attention and precision.

The interesting results obtained by Smith (1) need, however, to be confirmed by other works with a larger number of subjects. In addition, the current different treatments that may be used as preventive forms to control the TTH attacks are usually not corroborated by evidence-based medicine.

When we are dealing with children suffering from TTH, which are regarded as a prevalent and debilitating condition for both child and his or her family, the parents are often reluctant to accept a prescription with a pharmacological agent (7). They tend to prefer a non-pharmacological treatment as their first choice (7). One of the approaches to be tried in children is to stimulate a healthy lifestyle in order to avoid factors that could trigger headaches at both home and school (e.g., a good quality 


\section{Preventive Strategies}

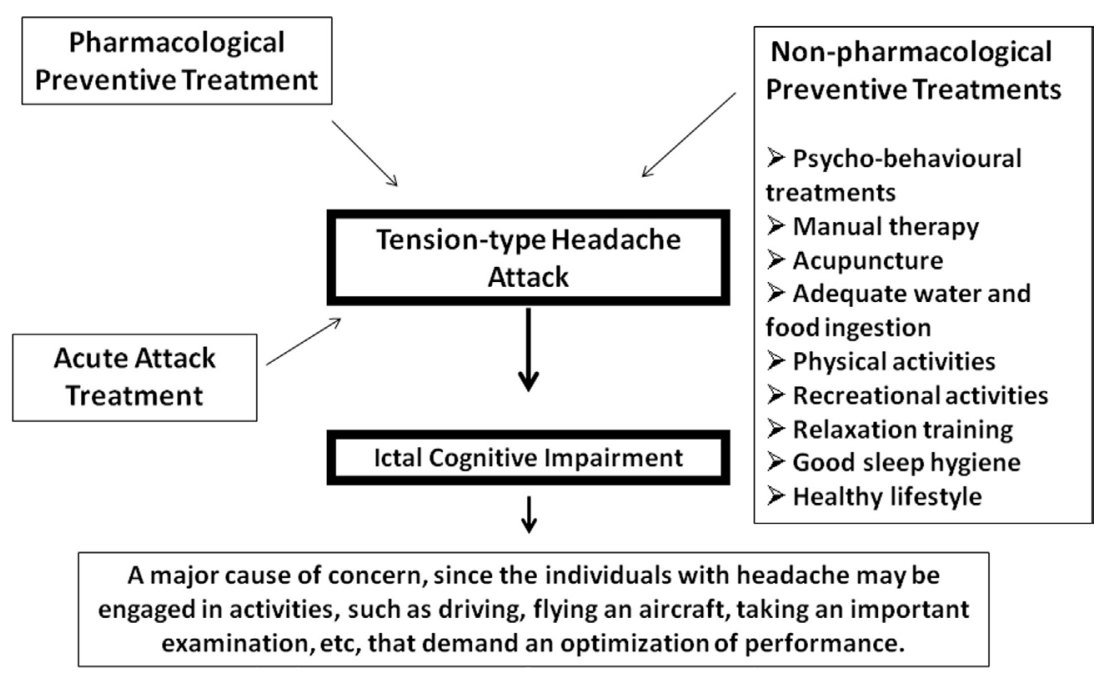

FIGURE 1 | Pharmacological and non-pharmacological strategies that may be adopted to reduce the possibility of a tension-type headache attack, which may impair cognitive function, representing a major cause of concern, when the individual is engaged in activities that demand an optimization of performance.

of sleep, adequate water and food ingestion, physical activity, and learning how to cope with psychosocial stressors) (7).

There are various other non-pharmacological strategies that may be adopted to reduce the possibility of a headache attack (Figure 1). Acupuncture, manipulation, joint range of motion, massage, cold packs, home exercise programs, advice on posture, muscle stretching techniques, retraining, and razor are some alternatives that might be of use (8). A recent update of a Cochrane review concluded that acupuncture is effective for treating frequent episodic or chronic TTHs (9).

Since the major concern here is the cognitive impairment during headache attacks, the use of preventive drugs to avoid such crises must bear in mind a possible additional cognitive deficit triggered by the choice of medication. The most widely used drug for treating TTH is amitriptyline, which, although it may attenuate a negative mood, can in fact worsen the cognitive symptomatology (10). There are a number of other pharmacological agents that have been employed as prophylactic treatment, such as antiepileptic drugs (sodium valproate, topiramate, and gabapentin), benzodiazepines, botulinum toxin, noradrenergic and specific serotonergic antidepressants (mirtazapine), serotonin re-uptake inhibitor antidepressants, and other tricyclic antidepressants (11); however, memory impairment has been reported with some of them.

A recent review (12) concluded that, in epileptic patients, some antiepileptic drugs, namely phenobarbital, phenytoin, topiramate, and zonisamide, can impair cognitive function. On the other hand, sodium valproate, carbamazepine, gabapentin, and oxcarbazepine do not appear to affect cognition. In addition, phenobarbital, valproate, gabapentin, topiramate, levetiracetam, and zonisamide may produce adverse behavioral side effects, although carbamazepine was considered neutral by the authors (12).

Nevertheless, venlafaxine and SSRIs were no more effective than amitriptyline or placebo in reducing the attack frequency in chronic TTH (13).

Recent evidence suggests that it is indeed possible to protect cognitive functioning by pharmacoterapy, despite the fact that its effectiveness has not been demonstrated to date in children or adolescents. The newly introduced drugs, levetiracetam and lamotrigine, seem to induce positive cognitive effects, with an additional positive behavioral effect being observed with the latter.

Topiramate is another drug widely used to prevent migraine and has also been used to treat chronic TTH, but it is well established that it can cause a major deterioration in cognition (particularly in relation to verbal fluency, memory spans, and working memory) (14). Since levetiracetam may improve cognitive abilities, it was tried to overcome the cognitive impairment induced by topiramate using it in combination with levetiracetam. Unfortunately, they were unsuccessful, using an experimental model with rats (15). In this context, a small series of patients with topiramate-related cognitive and language dysfunction improved with donepezil (16).

The ethical, legal, and public policy implications of the use of drugs, such as donepezil, rivastigmine, galantamine, caffeine, nicotine, amphetamines, modafinil, and memantine to enhance cognition in cognitively healthy individuals is reviewed by Mehlman (17). In this concern, memantine (18) and dextroamphetamine (19) were used for prophylaxis of chronic TTH.

Over-the-counter medications are largely used in the acute therapy for TTH (20). A recent review reported that the number 
needed to treat values for being pain-free at $2 \mathrm{~h}$ compared with placebo were 8.7, 8.9, and 9.8, respectively, for paracetamol 1,000 mg, ibuprofen $400 \mathrm{mg}$, and ketoprofen $25 \mathrm{mg}$ (21).

Another possible form to treat acute TTH in adults and children above 6 years is the local topical use of $10 \%$ peppermint oil in ethanol, whose beneficial effects are comparable to that of paracetamol or acetylsalicylic acid (22).

In conclusion, in the future, new drugs are likely to be introduced or the agents in the current therapeutic arsenal are to be used in combination in order to overcome possible adverse cognitive and/or behavioral side effects that might occur during preventive therapy in patients with incapacitating headaches.

\section{REFERENCES}

1. Smith AP. Acute tension-type headaches are associated with impaired cognitive function and more negative mood. Front Neurol (2016) 7:4. doi:10.3389/ fneur.2016.00042

2. Waldie KE, Welch D. Cognitive function in tension-type headache. Curr Pain Headache Rep (2007) 11(6):454-60. doi:10.1007/s11916-007-0233-1

3. Waldie KE, Hausmann M, Milne BJ, Poulton R. Migraine and cognitive function: a life-course study. Neurology (2002) 59(6):904-8. doi:10.1212/ WNL.59.6.904

4. Kalaydjian A, Zandi PP, Swartz KL, Eaton WW, Lyketsos C. How migraines impact cognitive function: findings from the Baltimore ECA. Neurology (2007) 68(17):1417-24. doi:10.1212/01.wnl.0000268250.10171.b3

5. Valença MM, de Oliveira DA. The frequent unusual headache syndromes: a proposed classification based on lifetime prevalence. Headache (2016) 56(1):141-52. doi:10.1111/head.12646

6. Costa Neto JJS. [Um continuum de crises entre cefaléia do tipo tensional e migrânea: elaboração de um escore diagnóstico baseado nas suas características clínicas]. Ph.D. thesis, Federal University of Pernambuco, Brazil [Portuguese] (2011).

7. Tornøe B, Andersen LL, Skotte JH, Jensen R, Jensen C, Madsen BK, et al. Specific strength training compared with interdisciplinary counseling for girls with tension-type headache: a randomized controlled trial. J Pain Res (2016) 9:257-70. doi:10.2147/JPR.S97826

8. Choi SY, Choi JH. The effects of cervical traction, cranial rhythmic impulse, and Mckenzie exercise on headache and cervical muscle stiffness in episodic tension-type headache patients. J Phys Ther Sci (2016) 28(3):837-43. doi:10.1589/jpts. 28.837

9. Linde K, Allais G, Brinkhaus B, Fei Y, Mehring M, Shin BC, et al. Acupuncture for the prevention of tension-type headache. Cochrane Database Syst Rev (2016) 4:CD007587. doi:10.1002/14651858.CD007587.pub2

10. Curran HV, Sakulsriprong M, Lader M. Antidepressants and human memory: an investigation of four drugs with different sedative and anticholinergic profiles. Psychopharmacology (Berl) (1988) 95(4):520-7. doi:10.1007/BF00172967

11. Ghadiri-Sani M, Silver N. Headache (chronic tension-type). Systematic review 1205. BMJ Clin Evid (2016). Available from: http://clinicalevidence.bmj. com/x/systematic-review/1205/overview.html (accessed February 05, 2016).

12. Aldenkamp A, Besag F, Gobbi G, Caplan R, Dunn DW, Sillanpää M. Psychiatric and behavioural disorders in children with epilepsy (ILAE Task Force Report): adverse cognitive and behavioural effects of antiepileptic drugs in children. Epileptic Disord (2016).

13. Banzi R, Cusi C, Randazzo C, Sterzi R, Tedesco D, Moja L. Selective serotonin reuptake inhibitors (SSRIs) and serotonin-norepinephrine reuptake inhibitors
Headache attacks can indeed impair cognitive function, representing a major cause of concern, since these individuals may be engaged in activities, such as driving, flying an aircraft, taking an important examination, etc., which demand an optimization of performance. Thus, the physician should consider prophylactic measures to avoid triggering attacks during the performance of such tasks.

\section{AUTHOR CONTRIBUTIONS}

The author confirms being the sole contributor of this work and approved it for publication.

(SNRIs) for the prevention of tension-type headache in adults. Cochrane Database Syst Rev (2015) 5:CD011681. doi:10.1002/14651858.CD011681

14. Brandt C, Lahr D, May TW. Cognitive adverse events of topiramate in patients with epilepsy and intellectual disability. Epilepsy Behav (2015) 45:261-4. doi:10.1016/j.yebeh.2014.12.043

15. Dhande P, Gonarkar S, Sanghavi D, Pandit V. Add-on effect of levetiracetam on cognitive activity of carbamazepine and topiramate treated healthy rats. J Clin Diagn Res (2015) 9(6):FF01-4. doi:10.7860/JCDR/2015/ 12654.6110

16. Wheeler SD. Donepezil treatment of topiramate-related cognitive dysfunction. Headache (2006) 46(2):332-5. doi:10.1111/j.1526-4610.2006.00348_1.x

17. Mehlman MJ. Cognition-enhancing drugs. Milbank Q (2004) 82(3):483-506. doi:10.1111/j.0887-378X.2004.00319.x

18. Lindelof K, Bendtsen L. Memantine for prophylaxis of chronic tension-type headache - a double-blind, randomized, crossover clinical trial. Cephalalgia (2009) 29(3):314-21. doi:10.1111/j.1468-2982.2008.01720.x

19. Haas DC, Sheehe PR. Dextroamphetamine pilot crossover trials and n of 1 trials in patients with chronic tension-type and migraine headache. Headache (2004) 44(10):1029-37. doi:10.1111/j.1526-4610.2004.04199.x

20. Diener HC, Gold M, Hagen M. Use of a fixed combination of acetylsalicylic acid, acetaminophen and caffeine compared with acetaminophen alone in episodic tension-type headache: meta-analysis of four randomized, double-blind, placebo-controlled, crossover studies. J Headache Pain (2014) 15:76. doi:10.1186/1129-2377-15-76

21. Moore RA, Derry S, Wiffen PJ, Straube S, Bendtsen L. Evidence for efficacy of acute treatment of episodic tension-type headache: methodological critique of randomised trials for oral treatments. Pain (2014) 155(11):2220-8. doi:10.1016/j.pain.2014.08.009

22. Göbel H, Heinze A, Heinze-Kuhn K, Göbel A, Göbel C. [Peppermint oil in the acute treatment of tension-type headache]. Schmerz (2016) 30(3):295-310. doi:10.1007/s00482-016-0109-6

Conflict of Interest Statement: The author declares that the research was conducted in the absence of any commercial or financial relationships that could be construed as a potential conflict of interest.

Copyright (C) 2016 Valença. This is an open-access article distributed under the terms of the Creative Commons Attribution License (CC BY). The use, distribution or reproduction in other forums is permitted, provided the original author(s) or licensor are credited and that the original publication in this journal is cited, in accordance with accepted academic practice. No use, distribution or reproduction is permitted which does not comply with these terms. 